\title{
MULHERES POMERANAS EM MOVIMENTO
}

\author{
Claudete Beise Ulrich' \\ Edineia Koeler ${ }^{2}$ \\ Erineu Foerste ${ }^{3}$
}

RESUMO: $\mathrm{O}$ artigo objetiva refletir sobre o protagonismo de mulheres pomeranas em movimentos sociais de transformação no município de Santa Maria de Jetibá, estado do Espírito Santo, partindo de uma problemática básica: em quais movimentos as mulheres pomeranas estão envolvidas e como a atuação delas constitui-se em desafio coletivo para elas mesmas e para todo Povo Tradicional Pomerano, que se encontra há 160 anos em terras capixabas? O artigo situa historicamente a chegada dos/as pomeranos./as nas terras capixabas. Aponta, então, para o protagonismo das mulheres pomeranas, através das narrativas de Selene e Gisela, no fortalecimento da luta coletiva por direito ao uso sustentável da terra, a partir da agricultura orgânica e agroecológica, objetivando saúde, alimentação saudável e uma educação que considere a cultura camponesa pomerana.

Palavras-chave: Narrativas. Mulheres Pomeranas, Povo Tradicional Pomerano, Agricultura orgânica e agroecológica.

\section{INTRODUÇÃO}

O presente artigo reflete sobre a narrativa de mulheres pomeranas em movimentos de transformação, que incluem mudanças no cultivo da terra, da saúde, da alimentação e também da educação. Estas mulheres residem em Santa Maria do Jetibá, no estado do Espírito Santo, distante 88,2 Km da capital Vitória. Quem são as mulheres pomeranas? Elas fazem parte do Povo Tradicional Pomerano, que chegou em terras capixabas há 160 anos. Erineu Foerste e Gerda Schutz

1 Pós-doutoranda em Educação na Universidade Federal do Espírito Santo. Pós-doutorada em História pela Universidade Federal de Santa Catarina. Doutora em Teologia: área de concentração educação e religião. Professora da Faculdade Unida de Vitória. Líder do Grupo de Pesquisa Religião, Gênero, Violências: Direitos Humanos da Faculdade Unida. Pesquisadora do Grupo de Pesquisa Culturas, Parcerias e Educação do Campo. Email: claudete@fuv.edu.br Orcid: http://orcid.org/0000-0002$\underline{9830-3768}$

2 Doutoranda em Educação pela Universidade Federal do Espírito Santo/UFES, em cotutela com a Fakultät für Kulturwissenschaften.Europa-Universität Viadrina, EUV-Frankfurt, Alemanha. Integrante do Grupo de Pesquisa Culturas, Parcerias e Educação do Campo. Professora- coordenadora da área de História - Secretaria de Municipal de Educação -SECEDU - Santa Maria de Jetibá. E-mail: edikoeler@hotmail.com Orcid: http://orcid.org/0000-0001-7202-937X

3 Pós-Doutor em Educação pela Universidade de Siegen/Alemanha. Doutor em Educação. Professor no Programa de Pós-Graduação em Educação na Universidade Federal do Espírito Santo. Líder Grupo de Pesquisa Culturas, Parcerias e Educação do Campo. E-mail: erineufoerste@yahoo.com.br Orcid: http://orcid.org/0000-0003-2846-0298 
Foerste demonstram que a partir do Decreto Federal n ${ }^{\circ}$ 6.040/2007 e do Decreto Estadual $n^{\circ}$ 3.248-R/2013 as/os Pomeranas/os foram declarados Povo Tradicional (FOERSTE; SCHÜTZ FOERSTE, 2017). O Povo Tradicional Pomerano guarda muitos elementos culturais, sendo um dos elementos importantes a língua pomerana.

A história da chegada deste povo no Brasil remete a meados do século XIX, quando muitas famílias tiveram que deixar a Pomerânia. O primeiro grupo de imigrantes de pomeranas/os com 117 pessoas desembarcou em terras capixabas em 28 de junho de 1859. Elas/es foram instalados às margens do Rio Santa Maria da Vitória, na Colônia de Santa Leopoldina, criada em 1857. Este povo migrou para o Brasil, pois havia uma política imigrantista do governo imperial, que buscava o branqueamento da raça, a ocupação de terras devolutas, a criação de uma classe média, a abertura de estradas, e a criação de colônias. Por outro lado, muitos destas/as imigrantes eram pessoas sem-terra, diaristas e pobres e viram no processo migratório também uma forma de melhorar as suas vidas e de suas famílias (RÖLKE, 2016). No Brasil vivem cerca de 300 mil descendentes do Povo Tradicional Pomerano e no Estado do Espírito Santo cerca de 130 mil (JACOB, 2012).

A cidade de Santa Maria de Jetibá é considerada a capital pomerana em terras capixabas. As mulheres pomeranas exercem um papel fundamental nas diferentes organizações sociais em suas comunidades. No entanto, as suas histórias de vida ainda são bastante invisibilizadas, silenciadas, pouco narradas e conhecidas. Tornar visíveis aquelas que foram ocultadas tem sido o objetivo das estudiosas feministas (LOURO, 1997). Michele Perrot afirma: "No entanto, o que importa reencontrar são as mulheres em ação, inovando em suas práticas, mulheres dotadas de vida, e não absolutamente como autômatas, mas criando elas mesmas o movimento da história" (PERROT, 1988, p. 187).

Este artigo busca trazer o movimento das mulheres pomeranas pela preservação da vida, que se mostra na forma de organização de suas famílias e comunidades. Segundo Ernani Mari Fiori "Aprender a dizer a sua palavra é toda a pedagogia, e também toda a antropologia" (FIORI, 1988, p. 18). As mulheres pomeranas narraram suas experiências de transformação, sendo este um processo pedagógico e antropológico fundamental de emancipação humana e de construção de identidade. Para nós, autoras e autor, o movimento de ouvir a narrativa e de registrá-la foi também um processo pedagógico libertador, de educação para a autonomia, pois as narradoras se assumiram como sujeitos históricos e éticos, situando-se contextual e historicamente nos movimentos de transformação no cuidado da terra, da saúde, da alimentação e da educação. As narrativas se realizaram
a partir de um processo dialógico, em que o ato de contar e de ouvir é de fundamental importância, acontecendo uma interação de compromisso entre as narradoras e as/o pesquisadoras/r, indo além da simples técnica, mergulhando na pluralidade da vida. Pesquisadoras/r e narradoras, numa relação de alteridade são, então, potencializadas para tornarem visível a história silenciada, perpassada por lágrimas e sorrisos, fracassos e vitórias (ULRICH, 2016, p. 125-126).

As mulheres pomeranas narradoras em nosso texto, nominadas de Selene e Gisela, de acordo com Walter Benjamim figuram entre as mestras e as sábias. Além de falar do acervo de suas próprias experiências, incluem também a experiência do seu grupo étnico. Segundo o autor, o dom do/a narrador/a "é poder contar a sua vida; sua dignidade é contá-la inteira. O narrador é a figura na qual o justo se encontra consigo mesmo" (BENJAMIN, 1994, p. 221). 
Desta forma, o artigo trata da narrativa de duas mulheres pomeranas atuantes nos movimentos da agricultura orgânica e agroecológica e como este envolvimento transformou a vida de suas famílias, da comunidade local, construindo também um encontro entre uma cidade interiorana e a capital do estado do Espírito Santo, através das feiras orgânicas. Primeiramente, vamos situar historicamente a chegada do Povo Tradicional Pomerano ao estado do Espírito Santo.

\section{SITUANDO HISTORICAMENTE A CHEGADA DAS/OS POMERANAS/OS NO ESTADO DO ESPIRITO SANTO}

As pesquisas de Ismael Tressmann indicam que os/as pomeranos/as são um povo alemão camponês originário da Pomerânia. A antiga Pomerânia era um território banhado pelo mar Báltico e situava-se entre as duas margens dos rios Vístula e Oder, estendendo-se até a Ilha de Rügen. O topônimo Pomerânia origina-se do eslavo antigo Pomorje, e significa "terra junto ao mar", que se traduz por Pomerania em latim e em inglês, Pommern ou Pommerland em alemão, e Pomorze em polonês. "A antiga Pomerânia possuía aproximadamente $38.408 \mathrm{~km} 2$ e era subdividida em Vorpommern (Pomerânia Ocidental ou Anterior) e Hinterpommern (Pomerânia Ocidental ou Posterior)". A maioria do/as pomerano/as que imigraram para o Espírito Santo vieram da Pomerânia Oriental, sendo pessoas empobrecidas, a maioria delas desprovidas da propriedade da terra. "Na época em que os primeiros pomeranos imigraram para o Brasil, no final da década de 1850, a Pomerânia era uma Província da Prússia” (TRESSMANN, 2005, p. 53-56).

Helmar Rölke lembra que, a partir do ano de 1850, iniciou-se um período cada vez mais sem perspectivas para os pequenos camponeses e os sem-terra na Pomerânia. Eram dois os motivos que levaram a isto: "a intensificação do uso cada vez mais 'racional' do solo; o início da industrialização, com a invenção da máquina a vapor” (RÖLKE, 2016, p. 64). Assim sendo, muitos/as pomeranos/ as imigraram para o Brasil, Estados Unidos, Austrália em busca de melhores condições de vida (TRESSMANN, 2005). De acordo com Tressmann

\footnotetext{
Os primeiros pomeranos chegaram ao Espírito Santo em 28 de junho de 1859. Subiram o rio Santa Maria da Vitória e se estabeleceram na recém criada colônia de Santa Leopoldina. Ocuparam, portanto, a região montanhosa do centro do Estado, denominada de Kulland, Terra Fria (TRESSMANN, 2005, p. 70).
}

A vinda destes imigrantes se deu antes da unificação da Alemanha (TRESSMANN, 2005). É interessante perceber que mesmo que a imigração alemã para o Espírito Santo tenha cessado em 1870 , as/os pomeranas/os

\footnotetext{
mantiveram o uso de sua língua, suas festas comunais, com seus rituais e danças, além dos costumes culturais e maritais, os atos mágicos que acompanham os ritos de passagem como batismo (inclusão das autoras e autor), confirmação (crisma), casamento e morte, a continuidade da narrativa fantástica da tradição oral camponesa (TRESSMANN, 2005, p. 15).A língua pomerana também é falada pelas narradoras Selene e Gisela. Geralmente, pessoas pomeranas são bilíngues, falam português e pomerano e muitas vezes, inclusive, são trilíngues falam pomerano, português e alemão. A língua pomerana "faz parte do patrimônio cultural
} 
imaterial de grande significado e importância para autoafirmação do Povo Tradicional Pomerano" (FOERSTE, SCHÜTZ FOERSTE, 2017, p. 10).

É fundamental também lembrar, que além, das causas da imigração da Europa para o Brasil, que apontam para crise europeia em meados do século XIX, gerando fome e miséria, devido mudanças no sistema econômico, a partir do capitalismo e do processo de industrialização, também o Brasil imperial tinha o seu projeto de colonização. Almejava-se com o incentivo da vinda dos imigrantes europeus que consistia na substituição da mão-de-obra escrava, em parte, por colonizadores europeus; política de "branqueamento"; colonização de terras que apresentavam um vazio demográfico, ocupação de áreas indígenas; cuidado das fronteiras (RÖLKE, 1996, p. 22-25). De acordo com Giralda Seyferth,

no Espírito Santo, o sistema foi o mesmo do Rio Grande do Sul e Santa Catarina: o centro da colonização alemã foram os vales superiores dos rios Jucu e Santa Maria da Vitória (área incluída na região denominada “de terras frias"); portanto, na região montanhosa do centro do Estado. Houve predominância de pomeranos (Prússia), embora a primeira colônia, Santa Izabel (1847), tenha sido fundada por imigrantes de Hesse e Hunsrück (SEYFERTH, 1988, p. 6).

Todos os núcleos coloniais acompanharam o mesmo perfil de nucleação, ou seja, foram assentados em áreas de floresta, com demarcação de terras que acompanhavam os vales dos rios, com formação de sociedades camponesas cuja economia baseava-se na pequena propriedade familiar. Os/as pomeranos/as foram colocados em lugares bem distantes do litoral, em meio às montanhas capixabas. Capixaba tem origem na língua Tupi e significa, roça, roçado, terra limpa para plantação. Pesquisas mostram que até 1873, ano em que cessou a imigração em massa, mais de dois mil pomeranos/as já haviam se instalado na região serrana do Espírito Santo (TRESSMANN, 2005, p. 62).

No entanto, os/as pomeranos sofreram vários tipos de violências desde o início, por exemplo, no processo de distribuição de terras receberam somente visitas esporádicas para fazer inventários e relatórios, faltavam escolas, religião que não fosse católica era apenas tolerada. Os/as pomeranos/ as eram e são em sua maioria protestantes de tradição luterana. As comunidades pomeranas haviam criado escolas comunitárias, as quais foram extintas com o processo de nacionalização instituído por Getúlio Vargas, em 1938. Portanto, sofreram um processo de negação de sua cultura, língua, religião e educação. (TRESSMANN, 2005, p. 97-100). Este processo criou, neste grupo, uma baixa autoestima, com o sentimento de que falam errado (BAHIA, 2000, p. 76).

Os/as pomeranos/as, em sua grande maioria, são camponeses. Neste sentido, é importante refletir sobre o termo Land e seu significado para os/as pomeranos/as. Land não significa somente a terra, mas tudo o que ela contém. O conceito Land é um elemento fundamental da cultura camponesa pomerana. De acordo com Tressmann

unidade de produção e consumo, juntamente com a propriedade, os animais, os objetos e valores que constituem seu modo de vida. Nos estudos sobre campesinato, sua significação seria equivalente ao termo inglês household. Em Português, o termo mais próximo para significar land é "colônia". O termo pomerano koloni é utilizado para designar a área rural em oposição a cidade. A colônia é tanto a terra quanto o produto do trabalho e do esforço familiar. Assim, 
a concepção de família camponesa está intimamente vinculada à ideia de colônia (TRESSMANN, 2005, p. 63).

Joana Bahia reflete na mesma direção de Tressmann e aponta para a importância do conceito de Land para as/os pomeranas/os

\begin{abstract}
$\mathrm{Na}$ língua pomerana, a palavra que designa a unidade familiar como unidade de produção de consumo, juntamente com a propriedade e os animais, objetos e valores que constituem seu modelo de vida, é Land. Sua significação seria equivalente na literatura sobre campesinato ao termo inglês household. $\mathrm{Na}$ língua portuguesa, temos o uso que fazem da palavra "colônia" que teria o mesmo significado de Land. A palavra "colônia" pode ser usada para se referir à própria terra e seu conjunto, ou à colônia de algum parente ou ainda à região de imigração pomerana no Estado do Espírito Santo. [...] A colônia e tanto a terra quanto o produto do esforço familiar (BAHIA, 2011, p. 47).
\end{abstract}

O conceito Land tratado por Bahia e Tressmann, portanto aponta para além da propriedade e do território. Representa também uma identidade social e a representação de práticas familiares relacionadas à terra, como a divisão do trabalho, herança, comercialização dos excedentes produzidos, entre outras (TRESSMANN, 2005). As mulheres têm um papel fundamental na Land. Elas são as principais responsáveis pela preservação da cultura e da língua pomerana. O trabalho na roça é igual para homens e mulheres. As mulheres, além de trabalharem igualmente com os homens na roça, são também responsáveis pelo cuidado da casa, das crianças, da horta, ordenha das vacas entre outros. Elas também são responsáveis pela feitura dos alimentos. Um elemento fundamental da gastronomia pomerana é o brote, um pão feito com farinha de milho e banana. São elas também que ensinam a língua pomerana e passam adiante os valores morais e religiosos para seus filhos e filhas. Portanto, é a partir do conceito de Land que forma a identidade social e cultural camponesa que vamos relatar algumas narrativas de duas pomeranas em movimento na agricultura orgânica e agroecológica e o que isto significa em termos de mudanças no plantar, colher e vender, alimentação, saúde e também na educação.

\title{
MULHERES POMERANAS EM MOVIMENTO: DE INVISIBILIZADAS, SILENCIADAS A PROTAGONISTAS DE TRANSFORMAÇÕES NA LAND - POR UMA AGRICULTURA ORGÂNICA E AGROECOLÓGICA
}

No romance Canaã (Graça Aranha, 1901), os colonos alemães (pomeranos) foram descritos como um povo de fácil adaptação; que tem energia do trabalho; que mais desenvolveram suas colônias. Vale destacar que embora se trate de um romance, que inaugura o pós-modernismo no Brasil, Canaã tem seu valor histórico reconhecido na versão comemorativa de 100 anos da obra. Nessa edição, o historiador capixaba, Renato Pacheco, após minucioso estudo da obra e da região retratada por ela, lhe acrescenta inúmeras notas comprovando muitos dos fatos narrados no romance. Daí resulta consultarmos a obra também como fonte histórica. Uma das passagens narradas nos interessa especialmente, embora a própria história do livro narre a violência que se praticava contra mulheres imigrantes, recém-chegadas ao Brasil, um caso particular aponta para a necessidade do 
despertar de lideranças femininas no meio rural. Independente do gênero, a corrupção contra imigrantes estava instalada entre "os homens da lei". Iniciava no processo de distribuição de terras aos colonos, onde se evidenciava a falta de regulamentação do sistema fundiário brasileiro (ARANHA, 2002). Em seguida, a distribuição dos lotes, magistrados brasileiros periodicamente "visitavam" os colonos para fazer inventários e relatórios.

A obra traz relatos de total submissão dos colonos aos "homens da lei", em um dos casos, o autor relata a história de uma jovem viúva que declara possuir quinhentos pés de café, mas o inventariante registra mil e quinhentos pés, com o propósito de aumentar suas despesas com impostos. O que mais chama atenção no caso, porém, é o que segue: A mesma viúva foi repreendida pelo fato de ter se apossado das terras do falecido marido, o que os magistrados (especialmente o escrivão Pantoja, responsável por interrogar a viúva) julgaram ser ilegal, visto que o lote de terras foi entregue ao marido e não à esposa (ARANHA, 2002). ${ }^{4} \mathrm{~A}$ jovem viúva de que trata o romance era possivelmente uma pomerana, que acabou sendo expulsa de suas terras por não ter o direito da posse. A luta por igualdade de direitos continua sendo uma das lutas feministas e também das mulheres pomeranas. Apresentamos, a seguir, narrativas de duas mulheres pomeranas que estão em movimentos por transformações em suas comunidades. Elas são lideranças protagonistas em Santa Maria de Jetibá-ES, na mesma cidade, a partir de onde Aranha escreveu seu romance. Pomeranas são também Selene e Gisela. Duas mulheres, que, no intuito de preservar a terra (Land), não no sentido da posse, mas no de proteção à vida, aderiram e integram desde a década de 1980, no município de Santa Maria de Jetibá, associações que buscam produzir alimentos saudáveis sem o uso de defensivos agrícolas. Como refletimos anteriormente, as/os pomeranos são de tradição religiosa luterana. Neste período histórico, a Igreja de Confissão Luterana no Brasil (IECLB) teve um papel fundamental na reflexão sobre a forma de tratar da terra, pois havia um uso excessivo de agrotóxicos por parte dos/as agricultores/as. Segundo o P. Emil Schubert

\begin{abstract}
a nossa luta pela agricultura orgânica começou por vários motivos. A motivação bíblico/teológica $\mathrm{E}$ as experiências de que o povo estava morrendo/se matando com o agrotóxico. E interessante saber: naquela época para receber empréstimo no banco para plantio de café, por exemplo, já vinha pronta a obrigação de quanto adubo químico e de quanto veneno era preciso usar (Entrevista realizada no dia 05 de outubro de 2019).
\end{abstract}

Ainda segundo o pastor, havia um grande índice de agricultoras/es doentes de câncer, bem como, muitas/os vieram a óbito devido a doença. Era necessário urgente mudar a forma de plantar e colher, pois a terra pertence a Deus (Salmo 24.1). Também o quinto mandamento afirma não matarás. As pessoas estavam se matando e também matando a própria terra com tanto uso de agrotóxicos. Assim, foram organizadas e criadas associações de agricultoras/es, objetivando a criação de uma agricultura orgânica e agroecológica.

4 O caso é descrito nas páginas 185-190 e comprovada pela nota número 26 na versão comemorativa: “O capitão escrivão Pantoja, apelidado por Graça Aranha de Maracajá, é o político coronel Francisco Rodrigues dos passos...” (Aranha, 2002, p. 292). 
Selene Hammer Tesch ${ }^{5}$, mulher pomerana, com 56 anos, casada há 40 anos, mãe de 4 filhos ( 1 falecido) e 5 filhas e avó de 4 meninas e 4 meninos. Ela vive no mesmo lugar onde nasceu, na localidade de Alto Santa Maria, em Santa Maria de Jetibá. O plantar, colher e cuidar fazem parte de sua vida desde a infância. Mas foi na vida adulta que esses termos ganharam forma, se tornaram projeto e objetivo de vida e se fizeram mais do que profissão. Selene transformou a profissão de agricultora em projeto de vida de sua família. O marido, os três filhos, as cinco filhas e famílias da comunidade abraçaram junto com ela o sistema de produção orgânica. Selene também lembra que uma das suas motivações foi a reflexão teológica e bíblica. Ela contou que era professora de Ensino Confirmatório (preparação para o rito da confirmação na IECLB), ela ensinava sobre o quinto mandamento não matarás. No entanto, ela mesma e sua família estavam plantando com agrotóxicos, envenenando a terra, as águas e a si mesmas. Esta reflexão também estava sendo conduzida pelas lideranças da Igreja e assim, assumiu que teriam que mudar de forma radical a forma de trabalhar na agricultura. Selene baniu o uso dos agrotóxicos e adotou como lema para sua vida "plantar sem matar, comer sem morrer".

Lembro que quando decidimos trabalhar com a agricultura orgânica, eu ensinava aos jovens na igreja luterana sobre o quinto mandamento que diz: 'Não matarás', e existem várias formas de matar. Os produtos com venenos também podem matar lentamente, isso me tocou muito fundo, então eu escolhi fazer da forma mais correta, suave, com qualidade, preservando a vida. (Entrevista realizada no dia 31 de agosto de 2019).

De acordo com a narradora, na época em que a família optou por trabalhar com o sistema orgânico de produção, houve muita desconfiança por parte de membros da comunidade que não acreditavam na proposta, gerando inclusive, alguns conflitos devido às exigências impostas pelo sistema de agricultura orgânica que acabava por influenciar nas propriedades vizinhas, tais como, adequação da água, e o cercamento natural da propriedade. Por fazer fronteira com vizinhos, estes acabavam por partilhar das cercas naturais que na agricultura convencional poderiam causar excesso de sombra. No entanto, tudo acabou se resolvendo diplomaticamente.

A partir da adoção da produção orgânica a propriedade agrícola da família Tesch se tornou cada vez mais diversificada e atualmente conta com mais de 300 variedades de produtos agrícolas, entre hortaliças, chás e temperos que são comercializados em feiras de produtos orgânicos da Grande Vitória, além de atender o Programa Nacional de Alimentação Escolar (PNAE) do Governo Federal.

Selene relatou que na trajetória para o sistema orgânico de produção, a família chegou a passar por necessidades:

No início a produção era tão fraca, tão fraca, que as pragas não deixavam as plantas crescerem. Agora temos muitos recursos pra lidar com isso de maneira rápida, mas naquela época não era assim. Lembro que por causa da falta de dinheiro, não conseguimos colocar gasolina no carro por mais ou menos cinco

$5 \quad$ Entrevista narrativa realizada no dia 29 de abril de 2019 e no dia 31 de agosto de 2019. 
meses para levar as crianças pra escola. Compramos uma bicicleta fiado para que eles pudessem ir, fazíamos todos os dias um trajeto de 20 quilômetros com eles. (Entrevista realizada no dia 31 de agosto de 2019).

Porém, de acordo com a própria narradora todo o esforço não foi em vão. Desde a Associação dos Produtores Santamarienses de Defesa da Vida (APSAD VIDA), (à qual também se filiaram a família de Gisela), criada em 1989 com o objetivo de organizar os produtores para a comercialização de produtos orgânicos da região de Santa Maria de Jetibá, a adesão e o apoio ao sistema de produção orgânica só cresceram. Várias outras associações foram surgindo, entre elas as ligadas a duas escolas agrícolas que ficam no município, adotando uma Pedagogia da Alternância. A Pedagogia da Alternância surgiu em 1935, como Maison Familiale Rural (MFR) ou Casa Familiar Rural (CFR). Segundo Nosella (2012), em decorrência da luta de um grupo de agricultores e do Padre Granereau, pároco de uma pequena capela localizada no Serignal-Péboldol, no interior da França. Acreditavam na possibilidade de uma educação que atendesse as necessidades do campo, e que ajudasse a ampliar os conhecimentos dos jovens baseando seus estudos a partir do meio em que estes vivem. Uma educação em que fosse possível o jovem estudar a partir da sua realidade. A ideia era não contrapor o ambiente rural ao urbano, mas reconhecer a dignidade do campo e compreendê-lo como produtor de culturas e não apenas de alimentos. De acordo com Nosella

A fórmula básica da pedagogia da alternância, como é fácil perceber, expressa um compromisso político bem preciso: rejeita a discriminação do homem e da cultura do campo, embasa o processo educativo na responsabilidade fundamental e inalienável da família e da comunidade, bem como na dialética entre teoria e prática (NOSELLA, 1977, p. 8).

No Brasil, a Pedagogia da Alternância foi criada ao final da década de 1960, sob a liderança do Pe. Humberto Pietrogrande, da Associação dos Amigos do Espírito Santo (AAES) e o Movimento de Educação do Espírito Santo (MEPES). Uma entidade filantrópica, cuja função era criar e manter a Escola Família Agrícola, o Centro de Formação e Reflexão (CFR), o Centro Comunitário Social, o hospital e creches no sul do Espírito Santo. Assim, em 1969, foi criada a Escola Família Agrícola de Olivânia (Anchieta), sendo discutida nesse mesmo período a criação de outras escolas em Alternância no sul do Espírito Santo.

Atualmente, o MEPES tornou-se a referência em Pedagogia da Alternância no Brasil, mantenedora de 17 escolas e prestando apoio pedagógico a escolas em Alternância por todo o país por meio do Centro de Formação e Reflexão (CFR) localizado no município de Piúma (ES). No município de Santa Maria de Jetibá, existem duas escolas que funcionam nesse sistema: A Escola Família Agrícola de São João do Garrafão, localizada no distrito de Garrafão, município de Santa Maria de Jetibá. A partir da década de 1980 houve uma mobilização em torno da criação de uma escola que atendesse alunos para além das quatro séries iniciais, realidade local até então. Neste movimento foi fundamental a liderança da Igreja Luterana e de uma mulher forte e batalhadora que mais tarde se tornou professora e diretora dessa e de outras escolas na região. Trata-se de Leonora Boone Sassemburg. Após reuniões e visitas às mais diferentes entidades educacionais, optaram

6 Embora nosso foco aqui sejam Selene e Gisela, não poderíamos deixar de mencionar Leonora, cujo trabalho pela educação em diferentes frentes, e redes é reconhecidamente louvável. Trataremos de sua trajetória oportunamente. 
pela Pedagogia da Alternância, considerada pelas mencionadas lideranças, a que melhor atenderia a uma comunidade cuja agricultura é essencialmente de base familiar.

Assim, em 1989 foram selecionados e enviados ao Centro de Formação do MEPES, três pessoas da comunidade, para realizarem o Curso de Formação em Pedagogia da Alternância, para que pudessem atuar como professores na escola. No mesmo ano a comunidade adquiriu a propriedade agrícola para instalação da Escola Família Agrícola de Garrafão, com o apoio da Prefeitura Municipal de Santa Maria de Jetibá. Neste período de implantação da escola, as atividades eram coordenadas pela Diretoria da Paróquia Evangélica de Confissão Luterana em São João de Garrafão.

Alto Santa Maria, que dista aproximadamente 20 quilômetros de Garrafão seguiu o exemplo e em atendimento a reivindicação da comunidade, a Secretaria de Estado de Educação - SEDU, acabou por atender a comunidade e permitiu essa forma de trabalho escola - no modelo da Pedagogia da Alternância que foi reconhecida por meio da Resolução CEE-ES 157/2000, de 20/09/2000, publicada no Diário Oficial de 26/01/2001. Nesta trajetória da educação em Alto Santa Maria, Selene, entre outras mulheres, teve participação ativa desde a idealização à concretização. As mulheres dessa região são as que mais marcam presença na escola.

Apesar de terem dificuldades para se encontrarem, também estão reunidas em associação a qual denominaram "As mães da terra". Criada por trabalhadoras rurais em 2008, atualmente é presidida por Selene, segundo a qual, um dos objetivos é a busca de formas alternativas de subsistência e luta pela garantia dos direitos das mulheres, da educação, do reconhecimento profissional, e do resgate da cultura pomerana. Outras entidades presididas por Selene são: a Associação Amparo Familiar de Santa Maria de Jetibá, a Cooperativa dos Agricultores Familiares da Região Serrana do Espírito Santo (Caf Serrana). Ambas voltadas especificamente para a agricultura familiar orgânica. Selene é uma referência em agricultura orgânica em nível nacional. Lidera vários grupos de agricultoras/es em Alto Santa Maria, município de Santa Maria de Jetibá. Participa de todo o processo de produção de alimentos desde a semeadura até a comercialização em feiras orgânicas (em Vitória, capital do estado, tem 24 feiras orgânicas e agroecológicas semanalmente), revelando sempre muita simplicidade, garra e força, características das mulheres pomeranas. Mãe, avó e esposa, Selene reconhece nas mulheres o potencial necessário para promover transformações. De acordo com a narradora

\begin{abstract}
As mulheres são fortes por natureza. Somos capazes de aturar muitas coisas e ainda sobreviver com tudo isso. As que são do campo mesmo chegam a ter jornada tripla. As mulheres que estão em movimentos também são criticadas por aquelas que estão. As próprias mulheres pomeranas não sabem que sofrem violências, seja moral, física e até sexual. A educação que receberam foi para obedecer, ser submissa. O dever das mulheres é ficar na cozinha, no trabalho. A partir das filhas, estamos tendo outras discussões sobre os direitos das mulheres. Isto também aprendemos também nos movimentos das mulheres. Temos direitos iguais e precisamos nos respeitar. (Entrevista realizada no dia 31 de agosto de 2019).
\end{abstract}

A consciência da importância do seu papel na comunidade fica explícito em suas palavras. Desenvolvendo trabalhos de liderança frente a organizações, faz mais do que representar agricultores e agricultoras, ela mostra às mulheres tudo o que elas representam e podem representar em uma sociedade: "mulheres são guerreiras, vamos nos abraçar a isso para seguir". Ela também disse 
que "uma agricultora que planta organicamente gera a paz. Quem gera paz na produção de comida orgânica gera paz na sociedade".

Entre as "mulheres guerreiras pomeranas" trazemos mais uma narrativa, cujo projeto de vida se insere na agricultura orgânica e na agroecologia. Trata-se de Gisela Boening Fleger, 53 anos, mãe de 2 filhas e dois filhos, avó de 1 neta e 1 neto, moradora da comunidade de Alto São Luís, também na cidade Santa Maria de Jetibá, ES. Desde jovem, transformou, junto com seu esposo, a propriedade agrícola da família Fleger em um ambiente ecologicamente sustentável e socialmente, integrador. Gisela integra a Associação dos Produtores Santamarienses em Defesa da Vida (APSAD-VIDA) desde a sua criação na década de 1980. Inicialmente a ideia era produzir alimentos saudáveis, livres de agrotóxicos, no entanto, devido à proximidade do sítio (sua Land) ao centro do município de Santa Maria de Jetibá, o local se tornou "alvo" de constantes visitas de estudantes, pesquisadores, simpatizantes da causa agroecológica. De modo que, de acordo com Gisela, o sítio foi sempre muito movimentado e os cafés oferecidos como cortesia acabaram se tornando um empreendimento. A família passou a ofertar a possibilidade de "cama e café" aos visitantes, isso o tornou em uma opção de lazer e a nova atividade, uma fonte de renda extra para a família Fleger.

A motivação foram os inúmeros visitantes, mas a organização resultou na realização de cursos realizados à noite, oferecidos pela Escola Graça Aranha. O casal Gisela e Valdemar, que já haviam concluído o Ensino Médio, voltaram a ocupar cadeiras na sala de aula. Valdemar se matriculou no curso técnico em meio ambiente e Gisela no de Turismo Rural - SEDU. Assim, puderam ao mesmo tempo adquirir conhecimentos em duas áreas próximas e que, na verdade, já praticavam em sua propriedade agrícola. Das trocas constantes de conteúdos estudados na escola, o casal resolveu adaptar a sua propriedade (sítio) para receber turistas, mas sem perder o vínculo com a agricultura. O próprio meio de produzir foi adaptado. Agora os turistas, que assim o desejassem, poderiam colher seus próprios alimentos com a implantação do sistema "colha e pague".

Antes desta mudança, a fonte de renda da família vinha da venda de produtos orgânicos nas feiras no próprio município e

Depois as portas começaram a se abrir na Grande Vitória de fazer feiras livres e aí começou, com essas feiras, alguns consumidores dessas feiras começaram a provocar a gente, no sentido de vir para o sítio e conhecer o trabalho que a gente desenvolvia aqui, querendo acompanhar de perto esse trabalho de agricultura orgânica. E aí, com isso, no ano de 2000, começamos com um tipo de hospedagem que é o cama e café, que é um sistema de hospedagem mais familiar, a gente recebe as pessoas na residência da gente, aí a coisa começou a andar. Porque até então a gente recebia essas pessoas aqui no sítio, mas elas vinham como visita, comiam... a gente, geralmente servia um café, servia um biscoitinho, ia todo mundo embora e a gente ficava com a bagunça. A gente nem sabia que isso já era agro turismo, que a gente poderia ganhar dinheiro com isso... então a partir de 2000 a gente começou a trabalhar de uma forma mais profissional (Entrevista realizada em 27 de outubro de 2019).

A adoção desse sistema de hospedagem levou à ideia do colha e pague, e com esse trabalho o sítio alcançou as memórias dos frequentadores com sua relação com a terra, pois de acordo com Gisela: 
E aí, até agora é muito prazeroso esse trabalho, porque as pessoas acabam relembrando dos tempos em que, muitas das pessoas que vem pra cá da cidade, já viveram na roça também, e eles acabam recordando os tempos em que eles viveram na roça também, e agora não é mais possível. E eles no final, acabam sempre levando uma cesta de verduras que eles mesmos podem ir para a horta e colher. (Entrevista realizada em 27 de outubro de 2019).

O trabalho, no entanto, não se restringiu ao sítio Fleger, pois ao integrar a associação APSAIDVIDA, aconteceu um trabalho de conscientização de outros membros da comunidade que acompanhavam de perto, em princípio, incrédulos, o trabalho realizado no Sítio Vale Verde e se convenciam de que é possível trabalhar e produzir sem o uso de agrotóxicos. Todo esse trabalho conta com a força da mulher pomerana. Gisela afirma que não é possível empreender um trabalho assim sem a ajuda da família. Os quatro filhos do casal já nasceram com o sítio funcionando no sistema agroecológico, e os três que ainda estão "em casa" abraçam a causa e se orgulham de contribuir com um planeta mais saudável.

A presença dos filhos e das filhas que permaneceram no sítio acompanhando e reproduzindo o trabalho dos pais é resultado de uma educação consciente com cuidado com a terra e tudo que ela contém. A luta pela agricultura orgânica e agroecológica se soma com a luta pela escolarização das/ os filhas/os em uma linha que segue critérios semelhantes, através da Pedagogia da Alternância. Esta foi uma iniciativa de movimento e luta das mães.

Os/as filhos/as de ambas as famílias, Fleger e Tesch estudaram em escolas agrícolas em regime de Alternância. A Pedagogia da Alternância é uma modalidade de ensino que busca a interação entre os/as estudantes que vivem no campo e a realidade vivenciada em seu dia a dia. Desta forma promove constantes trocas de conhecimentos entre seu ambiente de vida, de trabalho e o escolar. E neste contexto, as famílias se tornam parceiras da escola. Essas duas famílias, em especial, se destacam no sentido de receber alunos/as nas propriedades, mostrando na prática como funcionam os sistemas de produção orgânica e agroecológica.

Ambos os sítios Tesch e Fleger auxiliam as duas escolas - EEEFM Fazenda Emilio Schroeder e a EFA Garrafão - ambas com Pedagogia da Alternância. Quando as escolas mencionadas necessitam de lugares para a realização de estágios supervisionados, ou outras demandas, como aulas práticas, os dois sítios recebem os/as alunos/as. A escola do campo também visita e aprende com estas famílias nos modos de fazer e viver de forma orgânica e agroecológica.

Trabalho semelhante ocorre nas associações das quais essas famílias fazem parte, de modo que a casa, a escola e os grupos sociais mobilizadas em associações interagem, realizando, "involuntariamente" o seu papel educador conforme a Constituição Federal de 1988, cujo Art. 205. Diz que "A educação, direito de todos e dever do Estado e da família, será promovida e incentivada com a colaboração da sociedade, visando ao pleno desenvolvimento da pessoa, seu preparo para o exercício da cidadania e sua qualificação para o trabalho".

Portanto, os movimentos da agricultura orgânica e agroecológica envolvem muito mais do que somente o trabalho na terra. Além de não usar agrotóxicos, produzir uma alimentação saudável, envolve a educação alternativa, numa Pedagogia da Alternância. Selene também é uma grande produtora de chás, 170 tipos diferentes. Há também uma movimentação com saúde alternativa. Percebe-se que as mulheres pomeranas são protagonistas nos movimentos de transformação em suas famílias, tendo consequências em suas comunidades, mas também incidindo nas cidades e na capital do estado, através das feiras orgânicas, que se realizam semanalmente. São movimentos 
que estão ligados essencialmente com a soberania alimentar, alimentação saudável, lideranças das mulheres no associativismo, cuidado com as nascentes, a flora e a fauna.

\section{CONSIDERAÇÕES FINAIS}

O Povo Tradicional Pomerano encontra-se há 160 anos no estado do Espírito Santo. A sua origem é camponesa e sua identificação cultural e social se mostra com a Land, que engloba, a terra, a casa, os animais, a flora, a fauna, as águas. Outro elemento fundamental é o cultivo da língua pomerana, sendo patrimônio cultural imaterial de grande significado e importância para autoafirmação do Povo Tradicional Pomerano. A tradição religiosa luterana também tem sido fundamental para a resistência e a reorganização da vida deste povo.

As narrativas de Selene e Gisela falam do cuidado e do respeito com a sua Land, através da organização de seus sítios, com a plantação orgânica e agroecológica. Elas apontam para a importância do trabalho de sua tradição religiosa, especialmente no início da organização de suas associações. Selene e Gisela expressam uma nova vivência e espiritualidade com o cuidado com a terra e o compromisso com as gerações vindouras. Selene disse em sua entrevista "que diante de tanta destruição da natureza, ela se perguntou muitas vezes se Deus não se arrependeu de ter criado o ser humano".

Elas também tomaram a iniciativa de lutar por uma educação alternativa, através da Pedagogia da Alternância, que considerasse a importância da agricultura orgânica e agroecológica. Por isto, seus filhos e filhas estudaram em escolas agrícolas, que apontassem para um processo educativo de relação comprometido com o cuidado com a terra, alimentação saudável, medicina alternativa, soberania alimentar. Além do mais, destaca-se a liderança das narradoras em suas participações nas diferentes associações. A aprendizagem se dá na coletividade. Elas também apontaram para a importância do aprender intergeracional, na luta contra os diferentes tipos de violência que afetam a vida das mulheres.

As mulheres pomeranas, silenciadas e invisibilizadas, estão se tornando protagonistas de uma nova história, em movimentos pela vida e isto não tem sido sem conflitos. No entanto, elas resistem e estão em constantes processos de formação, não estão paradas, mas estão sempre aprimorando os seus conhecimentos. Elas mesclam modos de fazer e viver tradicionais com novas técnicas. Selene e Gisela, assim como outras mulheres pomeranas, são guardiãs da diversidade étnico cultural de Santa Maria de Jetibá, do Estado do Espírito Santo. As narrativas das mulheres pomeranas em movimento abrem-se ao diálogo com outras culturas, que objetivam transformações significativas no cultivo da terra, numa alimentação saudável, na medicina alternativa e na educação do campo, com uma pedagogia comprometida pela vida em sua integralidade.

Portanto, se é fato que em muitas civilizações a agricultura é uma "invenção" ou descoberta das mulheres, é fato que ela foi capitalizada pelos homens, estes, por sua vez, no intuito de lucrar desconsideraram o principal objetivo da produção agrícola: alimentar. Cabe novamente às mulheres a reinvenção, a redescoberta. E dessa vez a luta não é pelo controle da natureza e sim contra a ganância desenfreada do capitalismo que mata. Mata para produzir e mata por produzir, gerando, talvez, uma das maiores contradições de que se tem conhecimento: nunca antes na história da humanidade se produziu tantos alimentos quanto se produz hoje, em contrapartida, nunca se viu tantas pessoas passando fome. E talvez pudéssemos arriscar dizer, morrendo, inclusive, devido a forma como os alimentos chegam às mesas das famílias. Ora, primeiro, muitos dos alimentos 
produzidos pelo agronegócio passam pelo uso excessivo de agrotóxicos, o que por si só, já os tornam prejudiciais à saúde humana. Em seguida, muitos desses alimentos passam por um processo de industrialização para venda em grande escala, onde se acrescentam produtos totalmente desnecessários, como corantes, adoçantes, conservantes, entre outros. De modo que cabe a mulheres como Selene e Gisela resgatarem a produção de alimentos saudáveis, ainda que elas não tenham poder de interferir em escala global, mas ao produzir com o lema do "Plantar sem matar, comer sem morrer", elas avançam não só na prática, mas em toda uma filosofia de vida e multiplicam-na a potenciais agricultores/a quando recebem a escola em sua Land.

\section{REFERÊNCIAS}

ARANHA, Graça. Canaã (edição comemorativa de 100 anos). 2. ed. Rio de Janeiro: Ediouro, 2002.

BAHIA, Joana Maria. O tiro da bruxa. Identidade, magia e religião na imigração alemã. Rio de Janeiro: Garamand, 2011.

BENJAMIN, Walter. Magia e técnica, arte e politica. v. 1. São Paulo: Brasiliense, 1994. (Obras escolhidas).

BRASIL. Constituição (1988). Constituição [da] República Federativa do Brasil. Brasília, DF: Senado Federal, 1988.

BRASIL. Presidência da República. Decreto Federal nº.040, de 07 de fevereiro de 2007. Institui Política Nacional de Desenvolvimento Sustentável dos Povos e Comunidades Tradicionais (PNCPT). Disponível em: http://www.planalto.gov.br/ccivil_03/_ato2007-2010/2007/decreto/d6040.htm. Acesso em: 29 out.. 2019.

ESTADO DO ESPÍRITO SANTO. Governador de Estado. Decreto Estadual n. 3.248-R, de 11 de março de 2013. Cria a Comissão Estadual do Espírito Santo de Desenvolvimento Sustentável dos Povos e Comunidades Tradicionais (CEDSPCT-ES). Diário Oficial do ES, Vitória-ES, p. 11-12, 12 mar. 2013.

FOERSTE, Erineu; FOERSTE, Gerda Margit Schütz. Língua, Cultura e Educação do Povo Tradicional Pomerano. Educação em Revista, n. 33, p.1-24, 2017. Disponível em: http://www.scielo.br/pdf/edur/v33/ 1982-6621-edur-33-e153099.pdf. Acesso em 29 out. 2019.

JACOB, J. K. População pomerana no estado do Espirito Santo - Brasil. Vila Pavão: Secretaria Municipal de Cultura, 2012.

LOURO, Guacira Lopes. Gênero, sexualidade e educação: uma perspectiva pós-estruturalista. Petrópolis: Vozes, 1997.

NOSELLA, Paol . Uma nova educação para o meio rural. (Dissertação de Mestrado). São Paulo: Pontifícia Universidade Católica de São Paulo, 1977.

NOSELLA, Paolo. Origens da Pedagogia da Alternância no Brasil. Vitória: Edufes. 2012.

PACHECO. Renato. Canaã, romance singular. In: ARANHA, Graça. Canaã (edição comemorativa de 100 anos). ed. Rio de Janeiro: Ediouro, 2002, p. 9-23. 
PERROT, Michelle. Os excluidos da história: operários, mulheres e prisioneiros. Trad. Denise Bottmann. São Paulo: Paz e Terra, 1988.

RÖLKE, Helmar Reinhard. Descobrindo raízes: aspectos geográficos, históricos e culturais da Pomerânia. Vitoria: Secretaria de Produção e Difusão Cultural da Ufes, 1996.

RÖLKE, Helmar. Raízes da imigração alemã: história e cultura alemã no Estado do Espirito Santo. Vitória: Arquivo Público do Estado do Espírito Santo, 2016.

SEYFERTH, Giralda. Imigração e colonização alemã no Brasil: uma revisão da bibliografia. BIB, n. 25, p. 3-55, sem. 1, 1988. Disponível em: . Acesso em: 20 jun. 2019.

TRESSMANN, Ismael. Da sala de estar à de baile: estudo etnolinguístico de comunidades camponesas pomeranas do estado do Espírito Santo. Tese de Doutorado Rio de Janeiro: Universidade Federal do Rio de Janeiro, 2005.

ULRICH, Claudete Beise. Recuperando espaços de emancipação na história de vida de ex-alunas de escola comunitária luterana. Tese de Doutorado. Faculdades EST, São Leopoldo, 2006. 